\title{
Enterohaemorrhagic Escherichia coli O157:H7 target Peyer's patches in humans and cause attaching/effacing lesions in both human and bovine intestine
}

\author{
A D Phillips, S Navabpour, S Hicks, G Dougan, T Wallis, G Frankel
}

\begin{abstract}
Background-Enterohaemorrhagic Escherichia coli (EHEC) constitute a significant risk to human health worldwide, and infections, particularly with serogroup O157:H7, are associated with consumption of a variety of food and water vehicles, particularly food of bovine origin. EHEC cause acute gastroenteritis, bloody diarrhoea, and haemorrhagic colitis; up to $10 \%$ of cases develop severe complications, including the haemolytic uraemic syndrome, with a $5 \%$ case fatality. A virulence characteristic of enteropathogenic $E$ coli, the attaching/effacing lesion, is considered to be important in EHEC. However, although EHEC produce this lesion on cultured human cells, this has not been demonstrated on human intestinal mucosal surfaces. In addition, the initial site(s) of colonisation of EHEC in humans is not known.
\end{abstract}

Aims-To assess the association of EHEC O157:H7 with paediatric and bovine intestine using in vitro organ culture and determine if attaching/effacing lesions occur.

Methods-Ultrastructural analysis of in vitro intestinal organ cultures of human small and large intestine was used to investigate adhesion of 0157:H7 EHEC to intestinal surfaces. Bovine intestinal organ culture was used to examine the pathology produced by the same EHEC strain in cattle.

Results-The study showed that EHEC O157:H7 adhered to human intestinal mucosa. Binding and attaching/effacing lesion formation of $\mathrm{O} 157: \mathrm{H} 7$ in humans was restricted to follicle associated epithelium of Peyer's patches. The same strain caused attaching/effacing lesions on bovine mucosa.

Conclusions-O157:H7 targets follicle associated epithelium in humans where it causes attaching/effacing lesions. The same human isolate can cause attaching/ effacing lesions in cattle, indicating that similar pathogenic mechanisms operate across human and bovine species (Gut 2000;47:377-381)

Keywords: Escherichia coli; enterohaemorrhagic $E$ coli O157:H7; Peyer's patches; attaching/effacing lesion
Enterohaemorrhagic Escherichia coli (EHEC) comprise a group of emerging zoonotic pathogens of worldwide importance. ${ }^{1}$ The most prominent serotype within the EHEC group is O157:H7. ${ }^{2}$ In humans, EHEC cause acute gastroenteritis, bloody diarrhoea, and haemorrhagic colitis and are responsible for serious disease outbreaks associated with contaminated food. Up to $10 \%$ of cases develop severe complications including haemolytic uraemic syndrome (HUS) with a case fatality rate of approximately $5 \% .{ }^{1-3}$ The systemic diseases associated with EHEC infections are almost certainly linked to expression and translocation of the bacteriophage associated shiga toxin (Stx) across the gut epithelium. ${ }^{45}$ However, additional virulence factors, such as the attaching/effacing (A/E) phenotype ${ }^{67}$ and possession of the pO157 plasmid are required for expression of full virulence. ${ }^{8}$ Indeed, it has been shown that an O157:H7 strain depleted of the bacteriophage encoded Stx is as pathogenic, in terms of diarrhoeal disease, as the parent EHEC strain in animal models.

EHEC, in common with enteropathogenic $E$ coli (EPEC), possess the ability to form characteristic $\mathrm{A} / \mathrm{E}$ lesions on mammalian cells growing in culture ${ }^{10}$ and in animals. ${ }^{11}{ }^{12}$ The first gene to be associated with $\mathrm{A} / \mathrm{E}$ activity was the EPEC eae gene encoding intimin, an outer membrane protein adhesin essential for intimate bacterial attachment to eukaryotic host cells. ${ }^{13}$ The eae gene has also been detected in EHEC O $157^{14}$ and other EHEC serogroups, ${ }^{15}$ and has been shown to be required for colonisation in newborn piglets ${ }^{6}$ and calves. ${ }^{7}$ However, there are distinct differences between EPEC and EHEC making it important to compare their interaction with the intestine. At least four distinct intimin types, designated $\alpha$, $\beta, \gamma$, and $\delta$, have been identified, ${ }^{16}$ and importantly, different intimin types were found to be preferentially associated with defined EPEC and EHEC serotypes. These may confer different tissue targeting properties during infection. ${ }^{17}$ All of the genes necessary for $\mathrm{A} / \mathrm{E}$

Abbreviations used in this paper: $\mathrm{EHEC}$, enterohaemorrhagic Escherichia coli; A/E, attaching/effacing; HUS, haemolytic uraemic syndrome; EPEC, enteropathogenic $E$ coli; LEE, locus of enterocyte effacement; Esps, EPEC secreted proteins; Tir, translocated intimin receptor; PER, plasmid encoded regulator; IVOC, in vitro organ culture; SEM, scanning electron microscopy; TEM, transmission electron microscopy; FAE, follicle associated epithelium; Stx, shiga toxin. 
lesion formation map to a pathogenicity island termed the locus of enterocyte effacement (LEE), and include structural components of a type III secretory apparatus, secreted proteins (Esps; EspA, EspB, EspD), the translocated intimin receptor (Tir), and their respective chaperones (reviewed by Frankel and colleagues ${ }^{18}$ ). Recently it was shown that the LEE region from O157:H7 was unable to confer the attaching/effacing phenotype or secrete Esps when cloned in a laboratory $E$ coli strain background, indicating that there are functional and regulatory differences between EPEC and EHEC LEE regions. ${ }^{19}$ Other differences are that $\mathrm{O} 157: \mathrm{H} 7$ does not produce a tyrosine phosphorylated $\operatorname{Tir}^{20}$ and it takes longer to produce $\mathrm{A} / \mathrm{E}$ lesions on $\mathrm{HEp}-2$ cells. ${ }^{10}$

Cattle represent an important reservoir of EHEC, and human infection with contaminated bovine food products represents a major cause of food borne infection. The bacterial and host factors influencing colonisation and pathogenicity in cattle and humans remain poorly defined. Conventionally reared cattle are generally considered to be resistant to natural infection with $\mathrm{O} 157: \mathrm{H} 7$ but a carriage rate of up to $4 \%$ in healthy cattle has been reported. ${ }^{21}$ However, acute outbreaks of severe diarrhoea in cattle infected with this serotype have been described. ${ }^{22}{ }^{23}$ Moreover, $E$ coli O157:H7 can be virulent in neonatal calves ${ }^{7}$ but calves older than three weeks of age show only mild symptoms of pyrexia and diarrhoea following oral challenge. ${ }^{24}$

Although EHEC O157:H7 is believed to colonise the human large intestinal mucosa, ${ }^{1}$ association of EHEC O157:H7 and A/E lesion formation on human tissue has thus far not been demonstrated. In this in vitro study we investigated the interaction of EHEC O157:H7 with human mucosa and tested whether the same strain could cause $\mathrm{A} / \mathrm{E}$ lesions on bovine intestinal mucosa.

\section{Methods}

BACTERIAL STRAINS

EPEC E2348/69 (O127:H6) ${ }^{25}$ and a spontaneous Stx negative derivative of EHEC 84-289 $(\mathrm{O} 157: \mathrm{H} 7 \text {, termed } 85-170)^{26}$ were used throughout. The EHEC strain was originally isolated from a food handler in a Canadian nursing home, is fluorescent actin staining test ${ }^{10}$ positive on cultured HEp-2 cells (data not

Table 1 Patient age and number of enterohaemorrhagic Escherichia coli (EPEC), strains O127:H6 (E2348/69) and O157:H7 (85-170), that adhered to in vitro organ culture prepared from proximal small intestine, distal small intestine, Peyer's patches, and colonic samples

\begin{tabular}{|c|c|c|c|c|}
\hline & $\begin{array}{l}\text { Proximal small } \\
\text { intestine }\end{array}$ & $\begin{array}{l}\text { Distal small } \\
\text { intestine }\end{array}$ & Peyer's patch & Colon \\
\hline \multicolumn{5}{|l|}{ O127:H6 (E2348/69) } \\
\hline $\begin{array}{l}\text { Patient age (months) } \\
\text { (median (range)) }\end{array}$ & $101(41-178)$ & $100(18-193)$ & $131(51-180)$ & $136(53-184)$ \\
\hline No of samples & 8 & 10 & 8 & 8 \\
\hline $\begin{array}{l}\text { No of samples with } \\
\text { adhering bacteria (\%) }\end{array}$ & $8(100 \%)$ & $8(80 \%)$ & $6(75 \%)$ & $2(25 \%)$ \\
\hline \multicolumn{5}{|l|}{ O157:H7 (85-170) } \\
\hline $\begin{array}{l}\text { Patient age (months) } \\
\text { (median (range)) }\end{array}$ & $41(18-109)$ & $123(30-185)$ & $87(35-145)$ & $75(62-191)$ \\
\hline No of samples & 4 & 7 & 5 & 4 \\
\hline $\begin{array}{l}\text { No of samples with } \\
\text { adhering bacteria (\%) }\end{array}$ & 0 & 0 & $5(100 \%)$ & 0 \\
\hline
\end{tabular}

shown), and expresses a surface located $\gamma$-type intimin. Bacteria were stored routinely at $-70^{\circ} \mathrm{C}$ using a Microbank system (Prolab Diagnostics, Neston, UK). Prior to adhesion studies the strains were subcultured into brain heart infusion broth and incubated aerobically overnight at $37^{\circ} \mathrm{C}$ without agitation.

TISSUE SAMPLES

After fully informed parental consent and local ethics committee approval, human tissue was obtained during routine investigation of patients for potential intestinal disorders. Proximal small intestinal mucosa (fourth part duodenum or duodenojejunal flexure) was taken using either a double port paediatric Crosby capsule or grasp biopsy forceps during upper endoscopy (Olympus PCF paediatric endoscope). These patients were being investigated for abdominal pain, chronic diarrhoea, and/or failure to thrive, but no gastrointestinal cause for their complaint was determined. Terminal ileum, Peyer's patches, and transverse colon were taken using the grasp biopsy method during routine lower endoscopy. Peyer's patches can be recognised and selectively biopsied during endoscopy, ${ }^{27}$ a technique made easier by the application of video endoscopy. Patients undergoing lower endoscopy either had no cause found for their presenting symptoms of abdominal pain and/or bloody diarrhoea or had inflammatory bowel disease or a polyp diagnosed, but no involvement of the region biopsied for this study was detected on gross or microscopic observation. Median age and age range of the patients are shown in table 1. All endoscopic biopsies were taken from areas showing no obvious pathology or other abnormality, and all intestinal histology was reported to be normal in the material used in this study.

Bovine tissue was obtained from an adult Friesan cow undergoing routine slaughter at the Institute for Animal Health (Compton, Berkshire, UK). The cow had no recent history of diarrhoeal disease. A laparotomy was performed immediately after termination and a full thickness biopsy was taken from the continuous Peyer's patch region in the distal ileum and held at room temperature in in vitro organ culture (IVOC) medium $^{28}$ for transportation to the laboratory.

\section{ORGAN CULTURE ADHESION ASSAY}

IVOC was performed as described previously ${ }^{28}$ for eight hours. Briefly, $25 \mu \mathrm{l}$ of the overnight bacterial culture was inoculated onto the intestinal sample which had been placed mucosal surface up on a foam support in tissue culture medium (Dulbecco's modified Eagle's medium (with glucose and sodium bicarbonate), NCTC135 (with L-glutamine), newborn calf serum, and $0.5 \%$ D-mannose (Sigma Chemical Co, Dorset, UK)). Each bacterial strain was examined in human IVOC on at least three occasions using tissue from different children. For bovine IVOC, three biopsies were used. An uninoculated specimen was included with each experimental culture to exclude the possibility of in vivo bacterial colonisation. After incubation, 

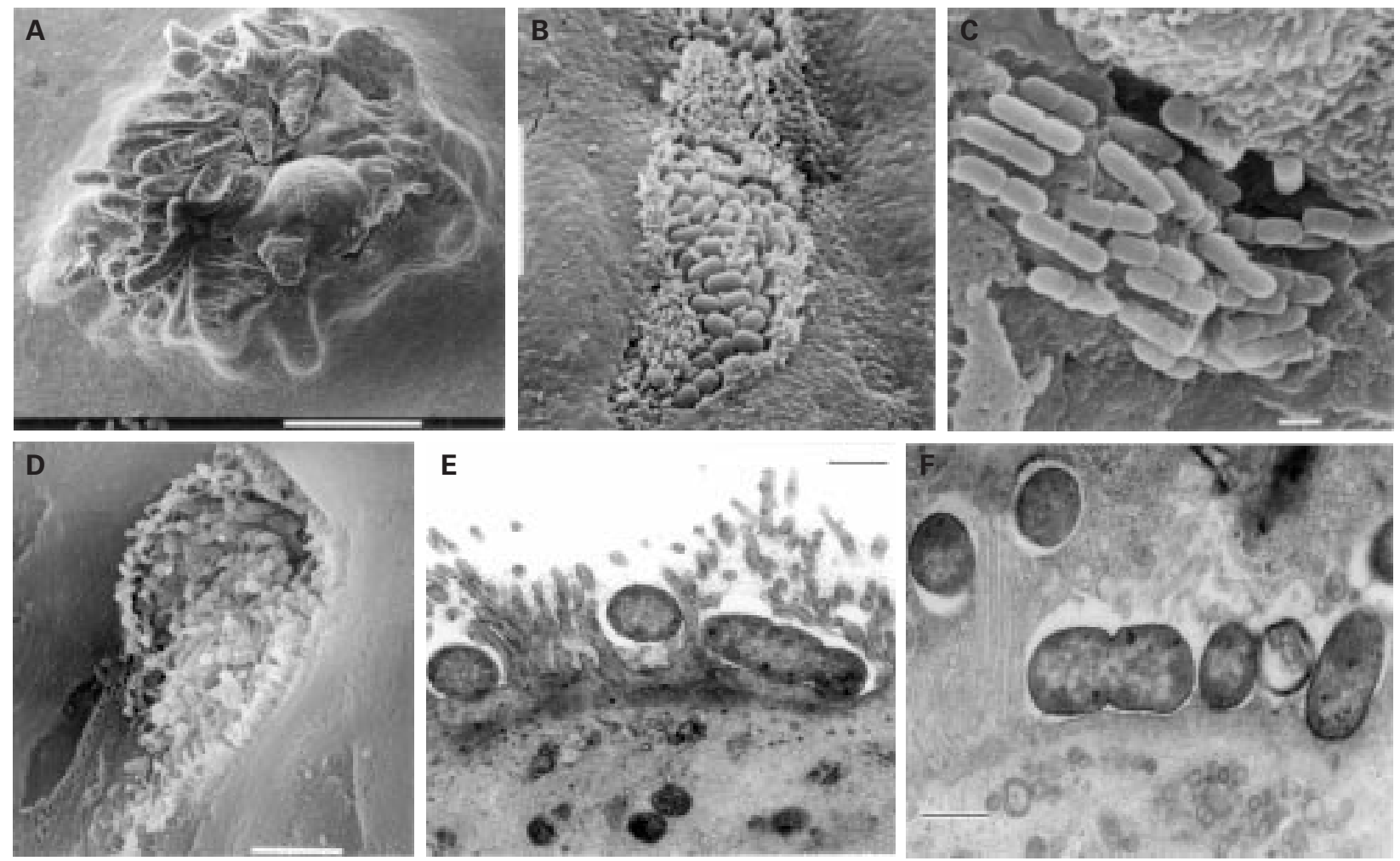

Figure 1 (A)-(E) are of human intestine. (A) In vitro organ culture (IVOC) sample showing presence of dome shaped lymphoid follicle (scanning electron microscopy $(S E M)$; bar $=500 \mu \mathrm{m})$. (B) Colony of EPEC E2348/69 on follicle associated epithelium (FAE) (SEM; bar=5 $\mu \mathrm{m})$. (C) EHEC strain 85-170 adhering to FAE in "log-jam"pattern (SEM; bar=1 $\mu \mathrm{m}$ ). (D) Colony of EHEC strain 85-170 on FAE (SEM; bar=5 $\mu \mathrm{m}$ ). (E)

Attaching/effacing lesion of EHEC strain 85-170 on FAE (transmission electron microscopy (TEM); bar=0.5 $\mu \mathrm{m}$ ). (F) EHEC strain 85-170 showing attaching/effacing lesion on bovine ileum (TEM; bar $=0.5 \mu \mathrm{m}$ ).

IVOC specimens were washed thoroughly three times with phosphate buffered saline to remove any non-adherent bacteria and then prepared for electron microscopy as described previously. ${ }^{28}$ Samples were fixed with $2.5 \%$ glutaraldehyde in $0.1 \mathrm{M}$ phosphate buffer, post-fixed in $1 \%$ aqueous osmium tetroxide, and dehydrated in 2,2 dimethoxy-propane. For scanning electron microscopy (SEM), specimens were transferred to absolute ethanol, critically point dried using liquid carbon dioxide in an Emitech K850 apparatus, mounted on aluminium stubs, sputter coated with goldpalladium using a Polaron E5100 sputter coater, and viewed in a JEOL 5300 scanning $\mathrm{EM}$ at an accelerating voltage of $30 \mathrm{kV}$. For transmission electron microscopy (TEM), post-fixed specimens were dehydrated in 2,2dimethoxypropane with three changes over nine minutes and embedded in $T A A B$ resin (TAAB Laboratories, Reading, UK). Ultrathin sections $(0.1 \mu \mathrm{m})$ were double stained with $2 \%$ uranyl acetate and lead citrate and examined in a JEOL 1200-EX II transmission electron microscope at an accelerating voltage of $80 \mathrm{kV}$.

\section{Results}

INTERACTION OF EHEC AND EPEC STRAINS WITH IVOC PREPARED FROM HUMAN GUT

The interaction of EHEC strain 85-170 with freshly biopsied human tissues, obtained from different sites within the gut, was examined and compared with the prototype EPEC strain E2348/69. In human gut IVOC assays, the domed mucosal surface overlying individual lymphoid follicles within Peyer's patches can be easily recognised in the scanning EM (fig 1A) so that bacterial adhesion to follicle associated epithelium (FAE) can be discriminated from adhesion to other epithelial sites. EPEC strain E2348/69 adhered to IVOC prepared from proximal small intestine, distal small intestine, and FAE of Peyer's patches (fig 1B) but showed limited adhesion to colonic samples (table 1). $\mathrm{A} / \mathrm{E}$ lesions were readily detected on IVOC samples infected with EPEC 2348/69 and the location of these lesions correlated with the adhesion pattern. In marked contrast, EHEC 85-170 were not detected adhering to the proximal small intestine, distal ileum, or transverse colon but were detected adhering to FAE in all Peyer's patch IVOC (fig 1C, D, table 1). Bacteria could not be detected adhering to the epithelium of villi neighbouring the follicle. Some bacterial colonies on FAE displayed a closely arranged parallel array of bacteria (fig $1 \mathrm{C})$, although others were not as organised. Transmission EM identified A/E lesion formation in these regions (fig 1E). FAE associated adhesion appeared to be randomly scattered over the FAE, and definite examples of adhesion to $M$ cells were not recognised. Indeed, $M$ cells were infrequently detected by SEM.

INTERACTION OF EHEC STRAIN 85-170 WITH IVOC PREPARED FROM BOVINE ILEUM

As cattle are a known reservoir of human $E$ coli O157 infection it was of interest to see if EHEC strain 85-170 could attach to bovine tissues 
and form $\mathrm{A} / \mathrm{E}$ lesions similar to those seen in the human samples. The interaction of EHEC strain 85-170 with cattle tissues was examined using a mucosal sample taken from the continuous Peyer's patch region in the distal ileum and held at room temperature in IVOC medium for transportation to the laboratory. Bacteria were detected binding to the surface of the tissue by microscopy and formed typical $\mathrm{A} / \mathrm{E}$ lesions (fig $1 \mathrm{~F}$ ). The target cells on the bovine mucosa to which the bacteria adhered could not be clearly identified, although the microvillous length suggested that they were absorptive epithelial cells.

\section{Discussion}

In the present study we have shown for the first time, using IVOC, that $E$ coli $\mathrm{O} 157: \mathrm{H} 7$ can attach to and cause $\mathrm{A} / \mathrm{E}$ lesions on human intestinal mucosal, and that the same strain causes $\mathrm{A} / \mathrm{E}$ lesions in conventional adult cattle intestine. These novel observations provide a potential link between mechanisms of intestinal colonisation operating across the two species, a factor that may contribute to the interspecies spread of infection. The success in visualising these phenomena in human tissue is probably due to several factors, including the short term nature of the organ culture (eight hours), choice of Peyer's patch material, and absence of Stx encoding genes in the O157:H7 strain used. Under in vivo conditions, patients would only present when symptoms are well advanced and the effects of Stx (including epithelial destruction ${ }^{29}$ ) are apparent, thus precluding identification of bacterial adhesion and $\mathrm{A} / \mathrm{E}$ lesion formation; postmortem material is inadequate for ultrastructural analysis of the surface epithelium. Using IVOC of human biopsies, we found that adhesion was limited to the FAE of Peyer's patches and that the pattern of adhesion showed similarities to the "logjam" pattern described for O157:H7 in cell culture experiments. ${ }^{30}$ The apparent discrepancy between $\mathrm{O} 157: \mathrm{H} 7$ adhesion to HEp-2 cells but not to most human intestinal areas, is a previously reported phenomenon for several mutant EPEC strains which readily bind to HEp-2 cells but show no adhesion to paediatric intestine. ${ }^{28}$ This may result from the complex brush border in humans versus the morphologically simple microvillous-like processes seen on HEp-2 cells. Our initial studies in cattle served to demonstrate that a human isolate of $\mathrm{O} 157: \mathrm{H} 7$ could cause an $\mathrm{A} / \mathrm{E}$ lesion in both species. Any comment on the pattern and sites of preferential adhesion in cattle would be premature and must await a more detailed investigation.

Several other bacterial pathogens are believed to exhibit preferential initial adhesion to FAE of Peyer's patches. This phenomenon has been described for human pathogens in animal models, for example Salmonella typhimurium, Listeria monocytogenes, and Shigella flexneri. ${ }^{31}$ Vibrio cholerae has been shown to adhere to formalin fixed human Peyer's patch epithelium ${ }^{32}$ but studies using unfixed human tissues have been limited. We previously demonstrated bacteria adhering to a proximal intestinal mucosal lymphoid follicle in a child with chronic diarrhoea and a Salmonella infection, ${ }^{33}$ raising the possibility of FAE involvement in long term bacterial colonisation. Our study shows that Peyer's patches may be involved in the initial events of EHEC colonisation. The specificity of this adhesion is uncertain as Peyer's patches are considered to be sites of antigen sampling. However, several bacteria express adhesins promoting binding to these regions (for example, long polar fimbriae in Salmonella, ${ }^{34} \mathrm{AF} / \mathrm{R} 1$ in RDEC- $1,{ }^{35} \beta-1$ integrin binding in Yersinia), ${ }^{36}$ and strains not expressing these adhesins show reduced Peyer's patch adhesion and less virulence. ${ }^{34} 37$

Our observations with human IVOC parallel those obtained using a natural EPEC infection (strain RDEC-1) in rabbits. This strain initially colonises FAE of rabbit Peyer's patches and then spreads to other intestinal regions; there is a time lag of 6-7 days between inoculation and development of diarrhoea, with Peyer's patch colonisation occurring within 24 hours, and ileal and colonic colonisation following 2-3 days later. ${ }^{38}$ The incubation period for O157:H7 is similar at approximately seven days. ${ }^{39}$ We would conclude from our in vitro observations that colonisation of other intestinal regions by $\mathrm{O} 157: \mathrm{H} 7$ is a subsequent event following colonisation of FAE. Certainly, histological studies in humans show extensive damage to colonic mucosa in the form of a haemorrhagic colitis, ${ }^{40}$ although the relative contributions of Stx circulating within capillaries and bacteria adhering directly to the mucosal surface (causing $\mathrm{A} / \mathrm{E}$ lesions and releasing toxin) in causing this damage is uncertain. The infective dose for O157:H7 can be small ${ }^{41}$ and this may appear surprising if the initial target of colonisation is restricted to FAE. However, Shigella species also have a small infective dose and show preferential adhesion to FAE of Peyer's patches. ${ }^{42}$ Both organisms are acid resistant, ${ }^{43}$ and this would assist passage through the stomach; growth would occur during transit to the ileocaecal region, where Peyer's patches are common, and reduced motility at the ileocaecal valve would also assist colonisation in this region.

We could not unequivocally demonstrate EHEC O157:H7 binding to $M$ cells as a potential mechanism for selective FAE binding in humans. However, recognition may be difficult as microvillous appearance is altered at sites of $\mathrm{A} / \mathrm{E}$ lesion formation. $M$ cells, unlike other epithelial cells, may express surface associated $\beta-1$ integrins $^{36}$ (and possibly other integrins). Intimin, a protein essential for $E$ coli O157:H7 colonisation in animal models, ${ }^{6744}$ can bind $\beta-1$ integrins in vitro ${ }^{45}$ and thus could target EHEC to $M$ cells. However, these cells were infrequently seen by SEM in FAE, a method routinely used to identify $M$ cells, and a more formal study is needed to establish their frequency and relevance in humans. A particular intimin derivative, intimin $\gamma$, is associated with $\mathrm{O} 157: \mathrm{H} 7$ and related serotypes ${ }^{16}$; replacing the eae gene (encoding intimin $\gamma$ ) of O157:H7 with eae (encoding intimin $\alpha$ ) results in colonisation spreading from the colon to the 
small intestine in gnotobiotic piglets. ${ }^{17}$ This raises the possibility that intimin $\gamma$, whether $M$ cells are involved or not, mediates the preferential binding of O157:H7 to FAE of Peyer's patches, and studies pursuing this line of investigation are underway.

We thank Jim Kaper and Stuart Knutton for providing strains, and Simon Murch and Mike Thomson for endoscopic skills in the provision of endoscopic biopsies, particularly from Peyer's patch areas. This work was supported by a joint BBSRC gran to ADP, TW, and GF.

1 Nataro JP, Kaper JB. Diarrheagenic Escherichia coli. Clin Microbiol Rev 1998;11:141-201.

2 Slutsker L, Ries AA, Greene KD, et al. Escherichia coli O157:H7 diarrhea in the United States: clinical and epidemiologic features. Ann Intern Med 1997;126:505-13.

3 Tarr PI. Escherichia coli O157:H7: clinical, diagnostic, and epidemiological aspects of human infection. Clin Infect Dis 1995;20:1-10.

4 Karmali MA, Petric M, Lim C, et al. Escherichia col cytotoxin, haemolytic uraemic syndrome, and haemorrhagic colitis. Lancet 1983;ii:1299-300.

5 Karmali MA, Petric M, Lim C, et al. The association between idiopathic hemolytic uremic syndrome and infection by verotoxin-producing Escherichia coli. 7 Infect Dis tion by verotoxin-

6 Donnenberg MS, Tzipori S, McKee ML, et al. The role of the eae gene of enterohemorrhagic Escherichia coli in intimate attachment in vitro and in a porcine model. $\mathcal{f}$ Clin Invest 1993;92:1418-24.

7 Dean-Nystrom EA, Bosworth BT, Moon HW, et al. Escherichia coli $\mathrm{O} 157: \mathrm{H} 7$ requires intimin for enteropathogenicity in calves. Infect Immun 1998;66:4560-3.

8 Levine MM, Xu JG, Kaper JB, et al. A DNA probe to identify enterohemorrhagic Escherichia coli of O157:H7 and other serotypes that cause hemorrhagic colitis and hemolytic uremic syndrome. I Infect Dis 1987;156:175-82.

$9 \mathrm{Li}$ Z, Bell C, Buret A, et al. The effect of enterohemorrhagic Escherichia coli $\mathrm{O} 157: \mathrm{H} 7$ on intestinal structure and solute transport in rabbits. Gastroenterology 1993;104:467-74.

10 Knutton S, Baldwin T, Williams PH, et al. Actin accumulation at sites of bacterial adhesion to tissue culture cells: basis of a new diagnostic test for enteropathogenic and enterohemorrhagic Escherichia coli. Infect Immun 1989;57: 1290-8.

11 Pai CH, Kelly JK, Meyers GL. Experimental infection of infant rabbits with verotoxin-producing Escherichia coli Infect Immun 1986;51:16-23.

12 Tzipori S, Wachsmuth IK, Chapman C, et al. The pathogenesis of hemorrhagic colitis caused by Escherichia coli O157:H7 in gnotobiotic piglets. F Infect Dis 1986;154 $712-16$.

13 Jerse $\mathrm{AE}$, Yu J, Tall $\mathrm{BD}$, et al. A genetic locus of enteropathogenic Escherichia coli necessary for the production of attaching effacing lesions on tissue culture cells. Proc Natl Acad Sci USA 1990;87:2842-4.

$14 \mathrm{Yu}$ J, Kaper JB. Cloning and characterization of the eae gene of enterohemorrhagic Escherichia coli O157:H7. Mol Microbiol 1992;6:411-17.

15 Huppertz HI, Busch D, Schmidt H, et al. Diarrhea in young children associated with Escherichia coli non-O157 organisms that produce Shiga-like toxin. F Pediatr 1996;128:3416.

16 Adu-Bobie J, Frankel G, Bain C, et al. Detection of intimins $\alpha, \beta, \gamma$, and $\delta$, four intimin derivatives expressed by attaching and effacing microbial pathogens. I Clin Microbiol 1998;36:662-8.

17 Tzipori S, Gunzer F, Donnenberg MS, et al. The role of the $e a e A$ gene in diarrhea and neurological complications in a gnotobiotic piglet model of enterohemorrhagic Escherichia coli infection. Infect Immun 1995;63:3621-7.

18 Frankel G, Phillips AD, Rosenshine I, et al. Enteropathogenic and enterohemorrhagic Escherichia coli: more subversive elements. Mol Microbiol 1998;30:911-21.

19 Elliott SJ, Yu J, Kaper JB. The cloned locus of enterocyte effacement from enterohemorrhagic Escherichia coli O157:H7 is unable to confer the attaching effacing phenotype upon $E$ coli $\mathrm{K}-12$. Infect Immun 1999;67:4260-3.

20 Ismaili A, Philpott DJ, Dytoc MT, et al. Signal transduction responses following adhesion of verocytotoxin-producing responses following adhesion of verocytotoxin
Escherichia coli. Infect Immun 1995;63:3316-26.
21 Mechie SC, Chapman PA, Siddons CA. A fifteen month study of Escherichia coli $\mathrm{O} 157: \mathrm{H} 7$ in a dairy herd. Epidemiol study of Escherichia coli
Infect 1997;118:17-25.

22 Orskov F, Orskov I, Villar JA. Cattle as reservoir of verotoxin-producing Escherichia coli O157:H7. Lancet 1987;2:276

23 Daniel R, Matthews L, Willshaw GA. Isolation of $E$ coli O157 from a calf with dysentery. Vet Rec 1998;143:56.

24 Brown CA, Harmon BG, Zhao T, et al. Experimental Escherichia coli O157:H7 carriage in calves. Appl Environ Microbiol 1997;63:27-32.

25 Levine MM, Berquist EJ, Nalin DR, et al. Escherichia coli strains that cause diarrhoea but do not produce heat-labile or heat-stable enterotoxins and are non-invasive. Lancet 1978;i:1119-22.

26 Tzipori S, Karch H, Wachsmuth KI, et al. Role of a 60-megadalton plasmid and Shiga-like toxins in the pathogenesis of infection caused by enterohemorrhagic Escherichia coli $\mathrm{O} 157: \mathrm{H} 7$ in gnotobiotic piglets. Infect Immun 1987;55:3117-25.

27 MacDonald TT, Spencer J, Viney JL, et al. Selective biopsy of human Peyer's patches during ileal endoscopy. Gastroenterology 1987;93:1356-62.

28 Hicks S, Frankel G, Kaper JB, et al. Role of intimin and bundle forming pili in enteropathogenic Escherichia coli adhesion to pediatric intestinal tissue in vitro. Infect Immun 1998;66:1570-8.

29 Keenan KP, Sharpnack DD, Collins H, et al. Morphologic evaluation of the effects of shiga toxin and $E$ coli shiga-like toxin on the rabbit intestine. Am f Pathol 1986;125:69-80.

30 McKee ML, O'Brien AD. Investigation of enterohemorrhagic Escherichia coli O157:H7 adherence characteristics and invasion potential reveals a new attachment pattern shared by intestinal E. coli. Infect Immun 1995;63:2070-4.

31 Jensen VB, Harty JT, Jones BD. Interactions of invasive pathogens Salmonella typhimurium, Listeria monocytogenes, and Shigella flexneri with $\mathrm{M}$ cells and murine Peyer's patches. Infect Immun 1998;66:3758-66.

32 Yamamoto T, Kamano T, Uchimura M, et al. Vibrio cholerae O1 adherence to villi and lymphoid follicle epithelium: in vitro model using formalin-treated human small intestine vitro model using formalin-treated human small intestine hemagglutinin levels. Infect Immun 1988;56:3241-50.

33 Phillips AD, Rice SJ, France NE, et al. Bacteria on duodenal lymphoid follicle from child with diarrhoea. Lancet 1978;i: 454 .

34 Baumler AJ, Tsolis RM, Heffron F. The lpf fimbrial operon mediates adhesion of Salmonella typhimurium to murine Peyer's patches. Proc Natl Acad Sci USA 1996;93:279-83.

35 Von Moll LK, Cantey JR. Peyer's patch adherence of enteropathogenic Escherichia coli strains in rabbits. Infect Immun 1997;65:3788-93.

36 Clark MA, Hirst BH, Jepson MA. M cell surface beta-1 integrin expression and invasin-mediated targeting of Yersinia pseudotuberculosis to mouse Peyer's patch M cells. Infect Immun 1998;66:1237-43.

37 Cantey JR, Inman LR, Blake RK. Production of diarrhea in the rabbit by a mutant of Escherichia coli (RDEC-1) that does not express adherence (AF/R1) pili. F Infect Dis 1989; 160:136-41.

38 Cantey JR, Inman LR. Diarrhea due to Escherichia coli strain RDEC-1 in the rabbit: the Peyer's patch as the initial site of attachment and colonization. F Infect Dis 1981;143:440-6.

39 Duncan L, Mai V, Carter A, et al. Outbreak of gastrointestinal disease in Sarnia, Ontario. Ont Dis Surveill Rep 1986;7:604-11.

40 Griffin PM, Olmstead LC, Petras RE. Escherichia coli 0157 : $\mathrm{H} 7$-associated colitis. A clinical and histological study of 11 cases. Gastroenterology 1990;99:142-9.

41 Bolton FJ, Crozier L, Williamson JK. Isolation of Escherichia coli O157 from raw meat products. Lett Appl Microbiol 1996;23:317-21.

42 Sansonetti PJ, Arondel J, Cantey JR, et al. Infection of rabbit Peyer's patches by Shigella flexneri: effect of adhesive or invasive bacterial phenotypes on follicle-associated epithelium. Infect Immun 1996;64:2752-64.

43 Benjamin MM, Datta AR. Acid tolerance of enterohemorrhagic Escherichia coli. Appl Environ Microbiol 1995;61: 1669-72.

44 McKee ML, Melton-Celsa AR, Moxley RA, et al. Enterohemorrhagic Escherichia coli O157:H7 requires intimin to colonize the gnotobiotic pig intestine and to adhere to HEp-2 cells. Infect Immun 1995;63:3739-44.

45 Frankel G, Lider O, Hershkoviz R, et al. The cell-binding domain of intimin from enteropathogenic Escherichia coli binds to beta 1 integrins. $\mathcal{F}$ Biol Chem 1996;271:20359-64. 